\title{
MULTIFORM SPECTRUM OF PULMONARY DISEASE IN LETHAL HIV INFECTION CASES IN LATVIA (2012-2016)
}

\author{
Regina Kleina ${ }^{1,3}$, Olga Fjodorova ${ }^{1}$, Anita Dabužinskienė², \\ Jurijs Nazarovs ${ }^{3}$, OKSANA Mahmajeva ${ }^{3}$ \\ ${ }^{1}$ Department of Pathology, Riga Stradiňš University, Riga, Latvia \\ ${ }^{2}$ Institute of Anatomy, Lithuanian University of Health Sciences, Kaunas, \\ Lithuania \\ ${ }^{3}$ Riga Eastern Clinical University Hospital, Pathology centre, Riga, Latvia
}

\begin{abstract}
In 2016, the proportion of HIV-infected persons in the Baltic countries was as follows: Latvia 18.5, Estonia 17.4, Lithuania 7.4 per 100,000 of population. The aim of our study was to evaluate the spectrum and morphology of combined lung pathologies in fatal HIV/AIDS cases in Latvia from 2010 to 2016. We did a retrospective review of the HIV/AIDS patients' medical autopsy case files and histological slides at the Pathology Centre of Riga Eastern Clinical University Hospital. All statistical data were processed in IBM SPSS Statistics 23. We analysed 455 cases - 311 (69\%) men, 134 (31\%) women. The mean age of the analysed patients was 40 years $( \pm 9 \mathrm{SD}$, range $22-68$ ). The conditions leading to death were opportunistic infections (OI) $28 \%$, tuberculosis $(\mathrm{TB})-23 \%$, wasting syndrome complicated by nonspecific pneumonia and sepsis or HIV/AIDS unrelated conditions - $27 \%$, malignancies - 11\% (B large cell lymphoma, primary and secondary cancers of the lung, Kaposi sarcoma), and end stage liver disease - $11 \%$. Lungs were affected in 380 cases $(83.5 \%)$. We identified 112 cases of tuberculosis (TB). In 21\%, it was isolated pulmonary TB, in $79 \%$ - disseminated TB. Additionally, OI were proved in $26 \%$ of these patients. The prevalence of OI was higher in patients who died from isolated pulmonary TB. We also identified 10 cases of disseminated atypical mycobacteriosis. Opportunistic infections were diagnosed in 126 persons - 77\% $(n=97)$ of them had one, but $23 \%(n=29)$ had two or more OIs. The most common isolated OI with lung involvement was
\end{abstract}


Pneumocystis jiroveci (PC) pneumonia ( $\mathrm{n}=71,15.6 \%) ; 10 \%$ had cryptococcosis, $1 \%$ - pulmonary aspergillosis and Candida pneumonia each. 40 patients (9\%) had disseminated cytomegalovirus (CMV). Among the various combinations of opportunistic infections, the most common was PC+CMV. 81\% of HIV patients were unemployed and prisoners with interrupted treatment. We concluded that our study revealed that combined opportunistic infections and TB were the most frequently observed pulmonary infections, followed by primary and secondary lung malignancies and bacterial pneumonia in HIV/ AIDS unrelated cases of multiorgan disease. Diagnostic difficulties occurred mainly in disseminated diseases due to nonspecific clinical presentation, similar appearance on imaging studies and limited bacterial diagnostic possibilities after death.

Keywords: pulmonary opportunistic infections; tuberculosis; malignancies; HIV

\section{INTRODUCTION}

In the present decade Latvia and Estonia have been among the European Union countries most heavily affected by the HIV/AIDS epidemic (Fig. 1). The main HIV transmission routes in Latvia are heterosexual contacts (40\%) and IVDU (25\%), but in $35 \%$ of cases the route of transmission is not reported $[18,37]$. In Lithuania and Estonia, the situation is similar $[5,10,20]$. Practitioners, radiologists and pathologists in the $21^{\text {st }}$ century - 35 years after the year 1982 when WHO accepted the word "AIDS" - are diagnosing very different lung diseases in HIV-infected persons. If we look at the past, in $198298 \%$ of respiratory complications were infectious in the USA [16]. HIV/AIDS-associated infections encountered in the WHO European Region include tuberculosis, bacterial infections, Pneumocystis jiroveci (PC) pneumonia, herpes infections,

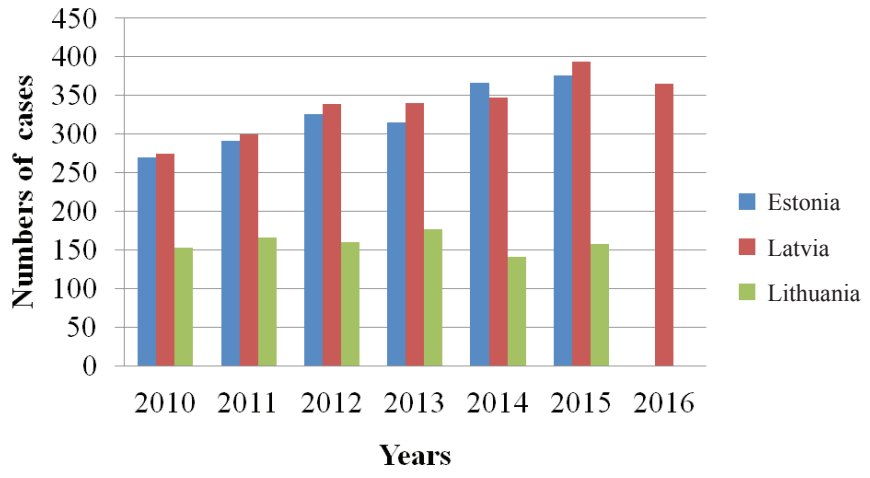

Figure 1. Newly diagnosed HIV cases in the Baltic states in 2010-2016. 
candida, cryptococcosis, toxoplasmosis, and Mycobacterium avium complex disease $[14,19]$. Involvement of two or more noncontiguous visceral organs is considered disseminated disease [14]. In 2015, PC was among the most common AIDS-defining diseases diagnosed in the EU with the prevalence of $20 \%$, followed by tuberculosis (14\%) and HIV wasting syndrome (11\%) $[24,32$, 33]. Commonly, PC pneumonia is associated with CMV pneumonitis $[2,11]$.

Cryptococcosis occurs at a CD 4 count below 100 cells $/ \mu$ l. The etiologic agent Cryptococcus neoformans is encountered in nature with a worldwide distribution; its site of entry is the respiratory tract [9]. In the case of a disseminated disease, the inflammatory reaction is typically weak because a disseminated disease is rapidly fatal and no significant cellular reaction can develop [8,9].

Pulmonary aspergillosis is a ubiquitous opportunistic fungus. The classic risk factors for this infection - neutropenia and corticosteroid use - are not always present [4]. Aspergillus can also colonize pre-existing pulmonary cavities in the case of tuberculosis, Pneumocystis jiroveci pneumonia or necrotizing bacterial pneumonia $[12,28]$. Opposite Candida pneumonia is a result of aspiration from oral mucosal lesions or hematogenous spread. In the latter case, the lesions are miliary, bilateral, involving the pleura. Disseminated multi-organ disease, a result of vascular invasion, is uncommon but highly lethal $[1,13,30]$.

Cytomegalovirus (CMV) causes localized pulmonary or disseminated invasive disease in AIDS [26]. Pre-ART (antiretroviral therapy) era studies, including autopsy-based, reported that CMV disease was recognized in endstage AIDS patients before death in up to $40 \%$ and at autopsy in up to $90 \%$ at that time [30]. Since the introduction of ART, CMV incidence and the related mortality among AIDS patients have declined. In ART era, patients who have CMV disease either do not receive or have failed to respond to antiretroviral therapy. Some authors suggest that CMV infection accelerates AIDS progression [26]. Mostly CMV disease is a result of reactivation of latent infection due to the fact that $50 \%-90 \%$ of adult general population depending on the world region are seropositive, as CMV and HIV share transmission routes [26, 30, 36].

Lungs can also be affected by Mycobacteriosis avium intracellulare. "Atypical" mycobacteria are ubiquitous environmental organisms found in soil and water. The disease is acquired through ingestion or inhalation of the organism but is not spread from person to person [25]. Macrophages fail to organize immune response and, instead of arranging a granuloma, they proliferate chaotically and place themselves in sheets which may totally obscure normal tissue structures. Langhans giant cells are absent or rare $[3,4]$. 
A co-infection of HIV is tuberculosis (TB), but it is not specific to HIV/ AIDS but common among these patients in endemic areas. HIV/AIDS patients are at high risk for a new TB infection, reinfection or reactivation. Pathogenetic relationships of HIV and TB are such that coinfection accelerates the natural course of both diseases [4]. In 2015 the proportion of HIV/TB patients in Latvia was $17.4 \%$ (in Estonia 12.4\% and in Lithuania 3.6\%). In the EU on average, this rate was $4.6 \%$ [5]. In advanced stages of HIV course, cavitary TB is uncommon and lower-lobe infiltrates or miliary dissemination as well as extrapulmonary TB usually occurs $[6,15]$. If extrapulmonary TB develops in immunocompetent individuals, no active pulmonary lesions are usually found at that time; however, in HIV/AIDS patients disseminated TB is characterized by simultaneous involvement of the lungs and other organs $[16,30]$.

Bacterial pneumonia in HIV/AIDS patients occurs at all levels of immunosuppression. It may be the first manifestation of HIV infection. Recurrent bacterial pneumonias are not uncommon, and two or more episodes in 12 months are considered to define AIDS. The etiology of pneumonia in HIV/AIDS is the same as in the general population. Streptococcus pneumoniae and Haemophilus influenzae are predominating. Staphylococcus aureus and Pseudomonas aeruginosa are more frequent than in the general population $[14,16,20]$.

Immunodeficiency renders individuals susceptible not only to opportunistic infections but also to certain malignancies. In HIV/AIDS, malignancies are either AIDS-defining (ADM) or non-AIDS-defining (NADM). Since the introduction of highly active antiretroviral therapy (HAART), the incidence of ADM has decreased, but the incidence of some NADM and the total cancer burden in HIV/AIDS population has increased [2, 14]. In comparison to general population, additional factors for NADM development in HIV/ AIDS patients are immunosuppression, high rates of oncogenic virus infection and the potential oncogenic effect of HIV itself $[29,31]$. It has been suggested that in ADM the severity but in NADM the duration of immunodeficiency play an etiologic role. This is supported by the fact that antiretroviral therapy is protective against ADM but not against NADM [18, 27, 35].

All ADM are related to oncogenic virus infections (HHV8 to Kaposi sarcoma, EBV and/or HHV8 to non-Hodgkin lymphoma, HPV to invasive cervical carcinoma). NADM development can also be related to oncogenic virus infections (Hodgkin lymphoma - EBV, hepatocellular carcinoma - HCV, HBV, anal cancer - HPV) $[14,16]$. Rates of infection with these viruses in the HIV/AIDS population are high due to shared transmission routes. Increased risk for developing lung cancer is attributable to the fact that cigarette smoking 
is more common, intense and usually initiated at younger age in HIV/AIDS patients than in the general population and also to recurrent pulmonary infections and chronic inflammation [22].

According to Latvian legislation all patients dying from dangerous infectious diseases including HIV have to undergo autopsy. To our knowledge not many autopsy-based studies on morbidity and mortality of HIV/AIDS population including large numbers of patients have been performed in Europe, including Baltic the countries $[3,7,22,36]$.

The aim of the study is to evaluate the spectrum, prevalence and morphology of pulmonary complications of fatal HIV/AIDS cases in Latvia from 20102016.

\section{MATERIAL AND METHODS}

Approval for this study was obtained from the Riga Stradiņš University Ethics Committee. The study is retrospective and descriptive and was done at the Pathology Centre of Riga Eastern Clinical University Hospital. We reviewed all the autopsy case files of 2010-2016 and selected HIV-positive patients who had died in large medical centres in Riga district in that period. From 455 lethal HIV/AIDS cases, we analysed 380 persons who had lung complications. We evaluated the gender, the age at the time of death, pathological and actual clinical diagnoses. The main diagnosis, complications and comorbidities were taken into consideration. We analysed macroscopic organ appearance and histological samples. Data on the route of HIV transmission, social status of the patient and time of hospitalisation prior to death were collected where available. All statistical data were processed in Microsoft Office Excel 2007 and IBM SPSS Statistics 23.

\section{RESULTS}

All the patients included in our study died in Riga district hospitals in seven consecutive years. From all 455 patients included in our study, 314 (69.1\%) were males and 141 (30.9\%) were females. In each year that we analysed, the numbers of lethal cases among male patients were higher, although during the time period encompassed by the study, the numbers of lethal cases among female patients increased. $72 \%$ of the persons were unemployed at the time of death, $9 \%$ died in the prison hospital, $9 \%$ were disabled and only $10 \%$ reported 
being occupied, although the whole study population was in the working age. Hospital stay prior to death ranged from several hours to 280 days (median $=10$ days). The conditions leading to death included opportunistic infections (28\%), tuberculosis (23\%), malignancies (11\%), the end stage of liver disease (11\%) and wasting syndrome complicated by nonspecific pneumonia and sepsis or miscellaneous conditions not related to HIV/AIDS (27\%). Lungs were affected in practically all the above-mentioned situations, and there were 380 such cases (Table 1).

Analysing fatal opportunistic infections (OI), we found that $28 \%(\mathrm{n}=126)$ of the study population died from them. $77 \%(n=97)$ of them had one, and $23 \%$ $(n=29)$ had two or more OI at the time of death. The most common isolated OI were Pneumocystis jiroveci pneumonia, isolated pulmonary or CNS as well as disseminated cryptococcosis. The mean age at the time of death in this patient group was equal to that of the study population in general - 40 years $( \pm 9 \mathrm{SD}$, range 22-68). Males comprised $65 \%(n=82)$ and females $35 \%(n=44)$ of this group. Most commonly, lungs were affected by Pneumocystis jiroveci (PC). There were 71 patients ( $15.6 \%$ of the whole study population) with PC pneumonia at the time of death. Almost invariably, the gross autopsy finding in the lethal cases of PC pneumonia was total or subtotal diffuse bilateral pulmonary involvement with heavy, expanded, congested lungs. The diagnosis was

Table 1. Lung complications in fatal HIV/AIDS cases in 2010-2016 in Latvia

\begin{tabular}{lc}
\hline Lung involvement & Number of cases $(\mathbf{n}=\mathbf{3 8 0})$ \\
\hline Tuberculosis & 112 \\
\hline Non-specific pneumonia & 85 \\
\hline Pneumocystis jiroveci pneumonia & 71 \\
\hline CMV & 40 \\
\hline Criptococcosis & 35 \\
\hline Mycobacteriosis avium intracellulare & 10 \\
\hline Aspergillosis & 5 \\
\hline Candidiasis & 5 \\
\hline Secondary lung tumours & 5 \\
\hline Primary lung cancer & 3 \\
\hline Non-Hodgkin lymphoma & 5 \\
\hline Kaposi sarcoma & 4 \\
\hline
\end{tabular}


confirmed if characteristic PC pneumonia appearance was found on histological examination (Fig. 2).

Among various combinations of opportunistic infections, the most common was Pneumocystis jiroveci (PC) with cytomegalovirus pneumonia $(\mathrm{n}=15 ; 21$, $1 \%$ of all PC pneumonias). This combination was either isolated $(\mathrm{n}=12)$ or associated with one more nother opportunistic infection or with tuberculosis $(n=3)$. Gross changes were nonspecific. On microscopy, characteristic features of both pathogens could be visualized.

We found that 40 patients (9\% of the study population) had disseminated cytomegalovirus (CMV) infection at the time of death as documented in clinical charts. CMV infection was also associated with other diseases leading to lethal outcomes, most frequently with Pneumocystis jiroveci or nonspecific pneumonia caused by Streptococcus pneumoniae (Fig. 3).

Among fungal lung infections, we identified cryptococcosis, aspergillosis and Candida pneumonia. 47 patients (10\% of the study population) had cryptococcosis at the time of death. There were 10 cases of isolated pulmonary and 25 cases of disseminated cryptococcosis involving either lungs and brain or other organs as well as 12 cases of isolated CNS involvement which were not included in this research. At gross autopsy examination cryptococcal lesions were seen as areas of mucinous tissue lysis. On microscopic examination cryptococcal lesions in lungs appeared as masses of multiple monomorphic roundoval yeast cells surrounded by clear spaces on haematoxylin eosin staining with scarce inflammatory reactions (Fig. 4).

From 5 (1\% of the study population) cases of aspergillosis, 3 were aspergillomas and 2 were cases of bilateral necrotizing aspergillus pneumonia.

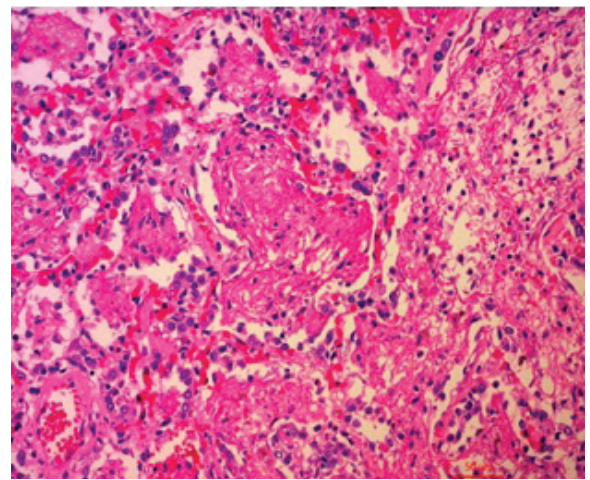

Figure 2. Pneumocystis jiroveci pneumonia (H\&E, x 100).

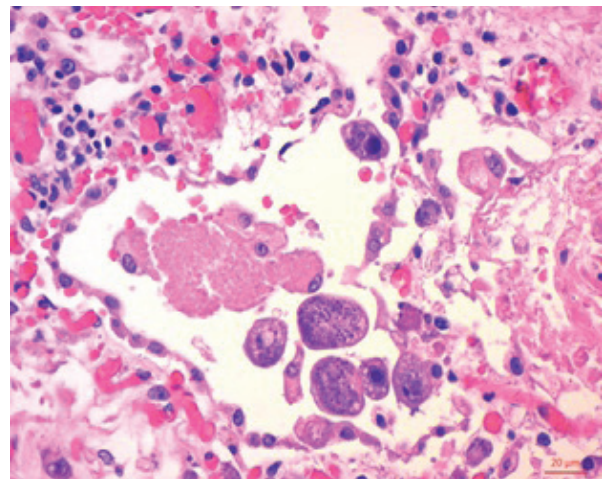

Figure 3. Combined Pneumocystis jiroveci and Cytomegalovirus pneumonia (H\&E, $\times 400)$. 
Fatal isolated candidiasis pneumonia was diagnosed in 5 cases ( $1 \%$ of the study population). On gross autopsy examination, pulmonary lesions were as multiple diffuse whitish infiltrates in different lobes, which are consistent with the fact that these patients had candidaemia prior to death as documented in clinical charts. The diagnoses were confirmed by identifying fungi within these lesions.

We also identified 10 cases of disseminated "atypical" mycobacteriosis (2\% of the study population). On gross examination, multiple whitish-yellowish miliary lesions with a diameter up to $5 \mathrm{~mm}$ were diagnosed in lymph nodes, lungs, kidneys, liver, spleen and intestines. The diagnosis was accepted if atypical mycobacteriosis was proved by laboratory tests and on histological examination non-necrotizing granulomas were identified in affected organs.

In $24.6 \%(n=112)$ of the whole study population, we diagnosed a co-infection with tuberculosis. In $93 \%(n=104)$ of all TB cases, the infection was fatal. In $21 \%(n=22)$ of lethal cases, it was isolated pulmonary TB and in $79 \%(n=82)$ disseminated but in others with healed tuberculosis of lungs. Males comprised $78 \%(n=81)$ and females $22 \%(n=23)$ of the patient group who died from TB. The mean age at the time of death was 38 years ( \pm 8 SD, range $22-59)$. As calculated by Levene's test, there was no statistically significant difference in age at the time of death between patients with isolated pulmonary and disseminated TB (level of significance 0.615 ), which shows that there is no association between the HIV/AIDS patients' age and the tendency to develop disseminated TB. According to available information from the clinical charts, in a number of cases TB was smear-negative (percentage not shown due to incomplete availability of clinical data). In a number of patients, TB was diagnosed repeatedly. In some of them, it had previously been treated successfully, and some had

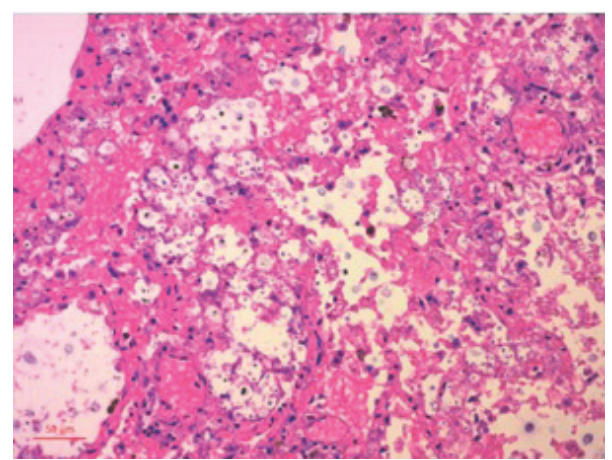

Figure 4. Cryptococcal lesions in lungs (H\&E, x 100).

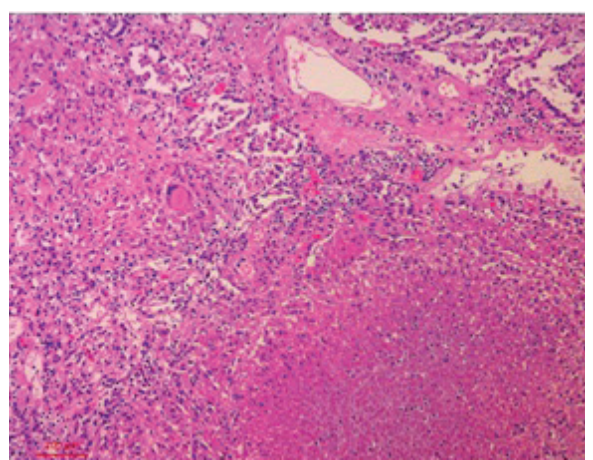

Figure 5. Pulmonary tuberculosis (H\&E, x 100). 
interrupted treatment. In a number of patients, resistance to first-line anti-TB medication was reported. On gross autopsy examination, pulmonary TB was almost invariably bilateral miliary disseminated (Fig. 5.). In all the cases of disseminated TB, multiple uniform miliary lesions were identified in lungs and other affected organs, most frequently thoracic and abdominal lymph nodes, liver, spleen, kidneys and CNS. Caseating lesions up to $0.5 \mathrm{~cm}$ in diameter were identified in lungs and other organs. Small intestine, pancreas, gonads and adrenal glands were involved less frequently. Tuberculous pleuritis and peritonitis were also identified in 4 cases. One patient who suffered from endobronchial TB developed a broncho-esophageal fistula. Both classic and atypical histomorphological TB patterns were present among the study population. Prevalence of opportunistic infections at the time of death in patients who died from any form of TB was $26 \%$, which is the highest among all the analysed patient groups. The prevalence of OI was higher in patients who died from isolated pulmonary TB than in patients who died from disseminated TB. Among 22 lethal cases of isolated pulmonary TB, 68\% $(n=15)$ had OIs where 10 of them had one and 5 had two or more OIs at the time of death. And among 82 lethal cases of disseminated TB, 12\% $(n=10)$ had OIs where 9 of them had one OI and one patient had a combination of Pneumocystis jiroveci and CMV pneumonia. Prevalence of viral hepatitis co-infection in this group was $40 \%$.

As calculated by Spearman's rank-order correlation test, there was a correlation between the presence of at least one OI that characteristically develops at a CD4 count below 200-50 cell/ $\mu \mathrm{l}$ at the time of death and a tendency to develop TB $(\mathrm{p}=0.01)$. This points to profound immunosuppression, given also the fact that the majority of TB cases were disseminated. The patients who had $\mathrm{TB}$ at the time of death but did not die from it died from end stage liver disease decompensation $(n=4)$ and progressive carcinomatous intoxication $(n=4)$.

We diagnosed 17 (11\% of our study population) cases of malignancy which had affected lungs in the analysed HIV/AIDS cases. The malignancy types were 5 lymphomas and 8 carcinomas: 3 of them primary ( 2 adenocarcinomas and 1 squamous cell cancer) but 5 metastatic (from thyroid gland, breast, stomach (Fig. 6), liver and pancreas). The average age of cancer patients was 46 years. Four Kaposi sarcomas affected lungs. The mean age at the time of death in this group was 39 years ( $\pm 8 \mathrm{SD}$, range $27-52$ ). The group was comprised of $71 \%$ males and $29 \%$ females. There was no statistically significant difference in the mean age at the time of death from AIDS-defining and non-AIDS-defining malignancies. 


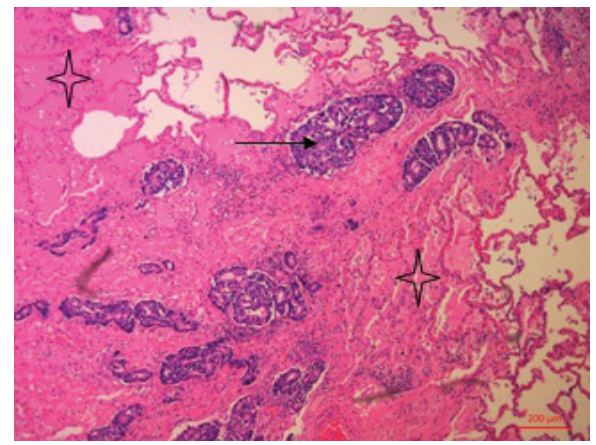

Figure 6. Gastric carcinoma metastases in lung $(H \& E, \times 100)$.

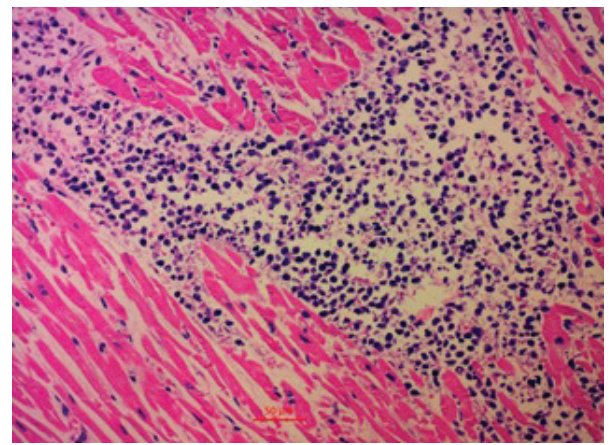

Figure 7. Diffuse large $B$ cell lung lymphoma invading myocardium $(H \& E, \times 200)$.

From 27 cases of lymphomas, lungs were affected in 5 cases only. Morphological and immunohistochemical examination proved that they were non-Hodgkin lymphomas at advanced stages (Fig. 7). Prevalence of opportunistic infections at the time of death in this group was $15 \%(n=8)$, that of tuberculosis $7 \%(n=4)$, and of viral hepatitis infection $42 \%(n=22)$.

$27 \%(n=122)$ of study patients died from the wasting syndrome and miscellaneous conditions. The mean age at the time of death was 40 years $( \pm 9 \mathrm{SD}$, range $22-67) .70 \%(n=86)$ of this patient group were males and $30 \%(n=36)$ were females. Almost invariably, these patients had nonspecific unilateral or, more frequently, bilateral pneumonia, sepsis, septic embolic events as well as aspiration and hypostatic pneumonia $(n=85)$. Many of the patients had signs of previous episodes of disseminated infectious processes, such as fibrotic changes in lungs.

\section{DISCUSSION}

If we compare HIV-related statistics of the Baltic states, we can see that the rates of new HIV cases in Estonia are approximately the same as in Latvia. But the background and dynamics of these data are not the same. The high rates of new HIV cases in Estonia are due to the active policy of HIV testing not only among risk groups but in all individuals of reproductive age [19, 32]. Pulmonary manifestation of HIV can be divided into two groups: patients who have received treatment with antiretroviral or chemoprophylactic drugs and those who have not $[16,18,19]$. Advanced pulmonary lesions at the time of death produced by opportunistic infections that typically develop at a CD4 count 
below $200 \mathrm{cells} / \mu \mathrm{l}$ indicate that patients are not taking antiretroviral therapy. Presence of cases where tuberculosis (TB) was diagnosed repeatedly, first-line anti-TB therapy resistance as well as disseminated disease at the time of death also indicates poor adherence to both antiretroviral and anti-TB therapy.

There are reports that the prevalence of HIV/TB coinfection is higher in intravenous drug users (IVDUs) [15]. In our study, the prevalence of viral hepatitis infection in patients who died from TB was $40 \%$, which is typical of populations where IVDU is the main HIV transmission route [23], but as it was also high in patients who died from other diseases - this only shows that IVDU is common among the Latvian HIV/AIDS population. Presence of the highest numbers of OIs at the time of death in lethal TB cases and the fact that most of $\mathrm{TB}$ cases were disseminated indicates profound immunosuppression in these patients [2].

Early development, aggressiveness and rapid progression of AIDS-defining lung malignancies (ADM) is attributed to immunosuppression of AIDS, but the nature of non-AIDS-defining malignancies (NADM) in HIV/AIDS patients is not yet understood. In our study, some of the NADM, including lung and liver cancers, were diagnosed in HIV/AIDS persons on average some 20 years earlier than in the general population and were in more advanced stages [27, 29]. One theory of these malignancies is that HIV accelerates immunological aging and induces genetical instability. Activation of proto-oncogens, alterations in cell cycle regulation, inhibition of tumour suppressor genes, induction of micro-satellite instability, induction of pro-angiogenesis signals promotes tumour growth and metastasis and makes infected tissues more susceptible to oncogenic factors by HIV [31]. In our study population, the prevalence of OIs at the time of death in patients dying from NADM was $17 \%$. This is relatively low in comparison to the patient group who died from TB. This might have some something to do with the fact that, besides immunosuppression, there may be another pathophysiological mechanism for NADM development. Pathologists must take into consideration that, on gross autopsy examination, different pathologies of lungs can mimic one another, and conditions that usually produce characteristic lesions in tissues can be present in an atypical way in HIV/AIDS.

In the EU, the mean age at the time of HIV diagnosis is 40 years now, while according to our results, this is the mean age of death for a Latvian HIV/AIDS patient with combined lung pathologies. This means that diagnoses of HIV in Latvia are established too late when patients are already terminal. While in the EU in general, HIV/AIDS patient mortality trends are shifting towards 
non-HIV/AIDS-related conditions, this shift cannot be seen in Latvia, and AIDS-related mortality is still high [37].

Already from 2002, there are studies about ART (mainly enfuvirtide (T20) and abacavir) as a cause of pneumonia and other respiratory diseases [17, 21]. Many antiretroviral agents are associated with toxicities and cause drug interactions. Around 30\% of HIV patients develop an immune reconstitution syndrome due to ART [34], and lung lesions are still present in HIV/AIDS patients.

The population must hope that, in the future, more patients will get ART and chemoprophylaxis, and the pulmonary complications of HIV will decrease in number. Unfortunately, a large number of persons does not know whether they have HIV, and they cannot access care and symptomatic treatment at the beginning of the disease.

\section{REFERENCES}

1. Asima B., Manasa K.K., Krishnam S.P. (2015). Candida colonization and speciation in HIV - positive patients in a tertiary care hospital. International Journal of Current Research, 2, 7, 12935-12939.

2. Bartlett J.G, Hirsch M.S., McGovern B.H. (2010). The stages and natural history of HIV infection. Available at: http://grmcolombia.com/imagenes/archivo/ descarga16.pdf [accessed 18.04.2017].

3. Beadsworth M.B., Cohen D., Ratcliffe L., Jenkins N., Taylor W., Campbell F., Beeching N.J., Azadeh B. (2009). Autopsies in HIV: still identifying missed diagnoses. International Journal of STD and AIDS, 2, 20, 84-86.

https://doi.org/10.1258/ijsa.2008.008271

4. Bykhalov A., Smirnov P. (2015). Morphological characteristics of inflammation in HIV-associated pulmonary tuberculosis with regard to the expression of myeloperoxidase. Archives of Pathology journal, 6, 77, 15-20.

https://doi.org/10.17116/patol201577615-20

5. Country progress report Lithuania, Vilnius. (2015). Available at: www.ulac.lt [accessed 19.07.2017].

6. Corbett E.L., Watt C.J., Walker J.N., Maher D., Williams B.G., Mario C., Dye R.C. (2003). The Growing Burden of Tuberculosis Global Trends and Interactions with the HIV Epidemic. Archives of Internal Medicine Journal, 163, 1009-1021. https://doi.org/10.1001/archinte.163.9.1009

7. Deeken J.F., Tjen-A-Looi A., Rudek M.A., Okuliar C., Young M., Little R.F., Dezube B.F. (2015). The Rising Challenge of Non-AIDS-Defining Cancers in HIV-Infected Patients. Clinical Infectious Diseases Journal, 9, 55, 1228-1235. 
8. Dyavaiah M., Geetha N.P. Yeasts: Candida and Cryptococcosis. Available at: https://www.esciencecentral.org/ebooks/bacterial-mycotic-infections/pdf/ Yeasts.pdf [accessed 12.04.2017].

9. Flávia G.A., Bittencourt C.S., Ferreira E., Severo L.C. (2009). Histopathology, serology and cultures in the diagnosis of cryptococcosis. Journal of the Sao Paulo Institute of Tropical Medicine, 5, 51, 225-259.

10. Gios L., Mirandola M., Toskin I., Marcus U., Dudareva-Vizule S., Sherriff N. et al. (2016). Bio-behavioural HIV and STI surveillance among men who have sex with men in Europe: The Sialon II protocols BMC. Public Health, 16, 212-222. https://doi.org/10.1186/s12889-016-2783-9

11. Griffiths P. (2006). CMV as a cofactor enhancing progression of AIDS. Journal of Clinical Virology, 4, 35, 489-492. https://doi.org/10.1016/j.jcv.2005.10.016

12. Guarner J., Brandt M.E. (2011). Histopathologic Diagnosis of Fungal Infections in the 21st Century. Clinical Microbiology Reviews Journal, 2, 24, 247-280. https://doi.org/10.1128/CMR.00053-10

13. Guazzelli L.S., Unis G., Xavier M.O., Severo C.B., Picon P.D., Severo L.C. (2009). Fungus ball in HIV-infected patients. Journal of the Sao Paulo Institute of Tropical Medicine, 6, 51, 345-348.

https://doi.org/10.1590/S0036-46652009000600007

14. Guidelines for the Use of Antiretroviral Agents in HIV-1-Infected Adults and Adolescents. Available at: https://aidsinfo.nih.gov/guidelines/html/1/adult-andadolescent-arv-guidelines/10/initiation-of-antiretroviral-therapy [accessed 18.04.2017].

15. Gupta R.K., Lawn S.D., Bekker L.-G., Caldwell J., Kaplan R., Wood R. (2013). Impact of HIV and CD4 count on tuberculosis diagnosis: analysis of citywide data from Cape Town, South Africa. The International Journal of Tuberculosis and Lung Disease, 8, 17, 1014-1022. https://doi.org/10.5588/ijtld.13.0032

16. Grubb J.R., Moorman A.C., Baker R.K., Massur H. (2006). The changing spectrum of pulmonary disease in patients with HIV infection on antiretroviral therapy. AIDS, 20, 1095-1107. https://doi.org/10.1097/01.aids.0000226949.64600.f9

17. Hewitt R.G. (2002). Abacavir hypersensivity reaction. Clin Infect Dis, 34, 11371142. https://doi.org/10.1086/339751

18. HIV/AIDS surveillance in Europe 2015. Available at: http://www.euro.who.int/__data/assets/pdf_file/0019/324370/HIV-AIDSsurveillance-Europe-2015.pdf.

19. HIV/AIDS treatment and care clinical protocols for the WHO European region. Management of tuberculosis and HIV Coinfection. Available at: http://www. euro.who.int/_data/assets/pdf_file/0004/78124/E90840_Chapter_4.pdf.

20. Laisaar K.T., Avi R., DeHovitz J., Uusküla A. (2011). Estonia at the threshold of fourth decade of AIDS era in Europe. AIDS Res Hum Retroviruses, 27, 8, 841-851. https://doi.org/10.1089/aid.2010.0223 
21. Lalezari J.P., Henry K., O’Hearn M., Montaner J.S., Piliero P.J., Trottier B., et al. (2003). Enfurvirtide, an HIV-1 fusion inhibitor, for drug-resistant HIV infection in North and South America. N Engl J Med, 348, 2175-2185. https://doi.org/10.1056/NEJMoa035026

22. Lanjevar D.N., Duggal R. (2001). Pulmonary pathology in patients with AIDS: an autopsy study from Mumbai. HIV Med, 2, 4, 266-271. https://doi.org/10.1046/j.1468-1293.2001.00079.x

23. Madelāne M., Vīksna L., Sture G., Ivanovs A. (2017). Cirkulējošo matricas metaloproteāžu-1, to audu inhibitoru un hialuronskābes līmeņa izmaiṇas pacientiem ar HIV monoinfekciju un koinfekciju ar C hepatīta vīrusu, 2017. Gada. RSU Zinātniskā konference. Tēzes, Rīga, 22.

24. Matulionyte R., Ambrozaitis A., Paulauskiene R., Aleksoniene R. (2006). Pneumocystis jirovecii pneumonia: an old disease with a new name. Medicina, 42, 8, 643-648.

25. Marcel C., Palmero D. (2008). Mycobacterium avium complex infection in HIV/AIDS patients. Expert Review of Anti-infective Therapy Journal, 3, 6, 351-363.

26. Meyer-Olson D., Schmidt R.E., Bollmann B.A. (2010). Treatment and prevention of cytomegalovirus-associated diseases in HIV 1 infection in the era of HAART. HIV Therapy, 4, 4, 413-436. https://doi.org/10.2217/hiv.10.30

27. Mitsuyasu R.T. (2014). Perspective Non-AIDS-Defining Cancers. Topics in Antiviral Medicine Journal, 3, 22, 660-665.

28. Nelson A.M., Hofman P. (2015). Human Immunodeficiency Virus Infection. In: Pathology of Infectious diseases. A Volume in the Series Foundations in diagnostic pathology, by Saunders, an imprint of Elsevier Inc., 96-97.

29. Robbins H.A., Pfeiffer R.M., Shiels M.S., Li J., Hall H.I., Engels E.A. (2015). Excess Cancers Among HIV-Infected People in the United States. Journal of National Cancer Institute 4, 107-118. https://doi.org/10.1093/jnci/dju503

30. Rosen M.J. (2008). Pulmonary complications of HIV infection. Respirology Journal, 2, 13, 181-190. https://doi.org/10.1111/j.1440-1843.2007.01167.x

31. Rubinstein P.G., Aboulafia D.M., Zloza A. (2014). Malignancies in HIV/AIDS: From Epidemiology to Therapeutic Challenges. AIDS Journal, 4, 28, 453-465. https://doi.org/10.1097/QAD.0000000000000071

32. Rüütel K., Uusküla A. (2006). HIV epidemic in Estonia in the third decade of AIDS era. Scandinavian Journal of Infectious Diseases, 38, 3, 181-186. https://doi.org/10.1080/00365540500388743

33. Samalavicius R., Serpytis M., Ringaitiene D., Grazulyte D., Bertasiute R., Rimkus B., et al. (2006). Successful use of extracorporeal membrane oxygenation in a human immunodeficiency virus infected patient with severe acute respiratory distress syndrome. AIDS Res Ther, 21, 11-37. 
34. Shelburne S.A., Visnegarwala F., Darcourt J., Graviss E.A., Giordano T.P., White A.C. Jr, Hamill R.J. (2005). Incidence and risk factors for immune reconstitution inflammatory syndrome during highly active antiretroviral therapy. AIDS, 19, 399-406. https://doi.org/10.1097/01.aids.0000161769.06158.8a

35. Shiels M.S., Pfeiffer R.M., Mitchell H. Gail, H., Hall I., Jianmin Li, et al. (2011). Cancer Burden in the HIV-Infected Population in the United States. Journal of National Cancer Institute, 9, 103-114. https://doi.org/10.1093/jnci/djr076

36. Spinello A., Nebuloni M., Magni C., Fasan M., Adorni F., Viola A., et al. (2009). Trends in the Postmortem Diagnosis of Opportunistic Invasive Fungal Infections in Patients with AIDS. American Journal of Clinical Pathology, 132, 2, 221-227. https://doi.org/10.1309/AJCPRAAE8LZ7DTNE

37. Vīksna L., Aldiṇš P., Stūre G. (2016). Mūsdienu mēris - HIV. Available at: https://arsts.lv/jaunumi/musdienu-meris-hiv [accessed 12.04.2017.].

\section{Address for correspondence:}

Regina Kleina

Department of Pathology

Riga Stradiňš University

16 Dzirciema Street, Rīga LV1007 Latvia

Phone +37129889981

E-mail: rkleina@inbox.lv 